\title{
PENGARUH PROMOSI, KUALITAS, DAN HARGA TERHADAP KEPUTUSAN PEMBELIAN SANDAL DAN SEPATU BRAND CARVIL DI CARVIL LAMPUNG - YOS SUDARSO BANDAR LAMPUNG
}

\author{
The Effect of Promotion, Quality, and Price on the Purchase Decision of Carvil \\ Brand Sandals and Shoes in Carvil Lampung - Yos Sudarso Bandar Lampung
}

\author{
Suryani $^{1}$, Suhartina ${ }^{2}$, Diana Yunita Dewi ${ }^{3}$ \\ Program Studi Administrasi Bisnis, FISIP, Universitas Tulang Bawang Lampung \\ suryani@utb.ac.id
}

\begin{abstract}
In this era of digitalization, the development of technology and information is running very rapidly, resulting in an increasingly fierce business competition. This makes producers to think critically, creatively, and innovatively to the changes that occur, both in the social, cultural, political and economic fields. The most important thing that a company should do to succeed in business competition is to try to build a company strategy to achieve the goal of increasing and retaining consumers of the Carvil Brand Store - Yos Sudarso in Bandar Lampung. Carvil remains consistent with current achievements, and continues to develop a variety of new and innovative designs for sandals and shoes for women, men, children, teenagers and adults to the elderly at Carvil Lampung brand stores - Yos Sudarso Bandar Lampung. This is descriptive quantitative, observational data collection techniques, questionnaires, secondary data, and documents conducted by research at the Carvil-Yos Sudarso brand store in Bandar Lampung. Based on the results of research that has been carried out to find empirical evidence about the influence of promotion, quality, and price on the decision to purchase Carvil brand sandals and shoes at Carvil Lampung - Yos Sudarso Bandar Lampung.
\end{abstract}

Keywords: price, quality, promotion, purchase decision

\begin{abstract}
ABSTRAK
Di era digitalisasi seperti sekarang ini perkembangan teknologi dan informasi berjalan sangat pesat, sehingga menghasilkan suatu persaingan bisnis yang semakin ketat. Hal ini membuat para produsen untuk berfikir kritis, kreatif, dan inovatif terhadap perubahan yang terjadi, baik dibidang sosial, budaya, politik maupun ekonomi. Hal terpenting yang sebaiknya dilakukan oleh perusahaan agar berhasil dalam persaingan bisnis yaitu berupaya membangun strategi perusahaan guna mencapai tujuan untuk meningkatkan dan mempertahankan konsumen Toko Brand Carvil - Yos Sudarso di Bandar Lampung. Carvil tetap kosisten dengan pencapaian saat ini, dan terus mengembangkan beragaman desain baru dan inovatif unuk sandal dan sepatu wanita, pria, anak-anak, remaja dan dewasa hingga orang tua di toko brand Carvil Lampung Yos Sudarso Bandar Lampung.Metode yang digunakan dalam penelitian ini ialah deskriptif kuantitatif, teknik pengumpulan data observasi, Kuesioner, data sekunder, dan dokumen yang dilakukan penelitian di Toko brand Carvil-Yos Sudarso di Bandar Lampung.Berdasarkan hasil penelitian yang telah dilakukan guna mencari bukti secara empiris tentang pengaruh promosi, kualitas, dan harga terhadap keputusan pembelian sandal dan sepatu brand Carvil di Carvil Lampung - Yos Sudarso Bandar Lampung.
\end{abstract}


Kata kunci: harga, kualitas, promosi, keputusan pembelian

\section{Pendahuluan}

Di era digitalisasi seperti sekarang ini perkembangan teknologi dan informasi berjalan sangat pesat, sehingga menghasilkan suatu persaingan bisnis yang semakin ketat. Hal ini membuat para produsen untuk berfikir kritis, kreatif, dan inovatif terhadap perubahan yang terjadi, baik dibidang sosial, budaya, politik maupun ekonomi. Hal terpenting yang sebaiknya dilakukan oleh perusahaan agar berhasil dalam persaingan bisnis yaitu berupaya membangun strategi perusahaan guna mencapai tujuan untuk meningkatkan dan mempertahankan konsumen.Selain itu, banyak perusahaan baru yang menawarkan berbagai produk dengan menerapkan strategi pemasaran yang bermacam-macam guna menarik perhatian calon konsumen untuk menggunakan produknya, terutama pasaran didunia digital.Banyak perusahaan yang mempromosikan produk dan perusahaannya lewat berbagai media digital dengan konten yang bervariasi konten tersebut berisi berbagai kelebihan dari produk yang dimiliki oleh perusahaan.Dengan menawarkan produk melalui berbagai media iklan. Diharapkan perusahaan nantinya dapat memperoleh keuntungan dari apa yang telah dilakukan sebelumnya dalam upaya mempromosikan produk. Seperti yang kita ketahui sebelumnya, bahwa sering dengan berkembangnya teknologi dan informasi sekarang ini banyak online shop yang bermunculan di berbagai kalangan, mulai dari remaja hingga kalangan orang dewasa.

\subsection{Perumusan Masalah}

Masalah yang perlu dikaji dalam penulisan penelitian ini adalah “ Pengaruh Promosi, Kualitas, Dan Harga Terhadap Keputusan Pembelian Sandal Dan Sepatu Brand Carvil Lampung Yos Sudarso Bandar Lampung ", adalah Sebagai Berikut:

1. Apakah promosi berpengaruh terhadap keputusan pembelian sandal dan sepatu brand Carvil Lampung - Yos Sudarso Bandar Lampung?

2. Apakah kualitas berpengaruh terhadap keputusan pembelian sandal dan sepatu brand Carvil Lampung - Yos Sudarso Bandar Lampung?

3. Apakah harga berpengaruh terhadap keputusan pembelian sandal dan sepatu brand Carvil Lampung - Yos Sudarso Bandar Lampung?

4. Apakah promosi, kualitas, dan harga, berpengaruh secara bersamasama terhadap keputusan pembelian sandal dan sepatu brand Carvil Lampung - Yos Sudarso Bandar Lampung?

\subsection{Batasan Masalah}

Agar permasalahan tidak melebar maka penulis hanya melakukan penelitian tentang Pengaruh Promosi, Kualitas, Dan Harga terhadap Keputusan Pembelian Sendal Dan Sepatu brand 
Carvil Lampung - Yos Sudarso Bandar Lampung tersebut.

\subsection{Tujuan Penelitian}

Adapun tujuan dari Penelitian ini adalah :

1. Untuk mengetahui pengaruh promosi terhadap keputusan pembelian Sandal Dan Sepatu brand Carvil Lampung -Yos Sudarso Bandar Lampung.Untuk Mengetahui Pengaruh Harga terhadap keputusan pembelian Sandal

2. Untuk Mengetahui pengaruh Kualitas terhadap keputusan pembelian Sandal Dan Sepatu brand Carvil Lampung - Yos Sudarso Bandar Lampung.

3. Untuk Mengetahui Pengaruh Harga terhadap keputusan pembelian Sandal Dan Sepatu brand Carvil Lampung -Yos Sudarso Bandar Lampung.

4. Untuk Mengetahui Pengaruh Promosi, Kualitas, Dan Harga secara bersama-sama terhadap keputusan pembelian Sandal Dan Sepatu brand Carvil Lampung - Yos Sudarso Bandar Lampung.

\section{Landasan Teori}

\subsection{Definisi Administrasi Bisnis}

Administrasi niaga adalah ilmu sosial yang mempelajari tentang proses kerja sama antara dua orang tau lebih dalam upaya untuk mencapai tujuan tertentu. Dengan kata lain, Definisi administrasi bisnis adalah ilmu yang fokus pada perilaku manusia.
Tujuan administrasi niaga / bisnis adalah untuk membangun suatu kerja sama yang paling menguntungkan antara dua orang atau lebih dengar memanfaatkan segala sumber daya yang ada. ( Sumber:htts:// w.w.w. pendidik.co.id.)

\subsection{Definisi Promosi}

Promosi merupakan kegiatan terpenting, yang berperan aktif dalam memperkenalkan, memberitahukan dan mengigatkan kembali manfaat suatu produk agar mendorong konsumen untuk membeli produk yang dipromosikan tersebut.

\subsubsection{Pengertian Bauran Promosi (Promotion Mix)}

Dalam mengkomunikasikan produknya ke konsumen, perusahaan dapat melakukan melalui beberapa alat promosi yang dikenal dangan bauran promosi.Bauran promosi adalah seperangkat alat yang digunakan oleh perusahaan untuk mengkomunikasikan produknya kepada konsumen.

Menurut Philip Kotler dan Kaller (2016:582) mendefinisikan masingmasing alat bauran promosi sebagai berikut:

\section{Advertising (Periklanan)}

Setiap dibayar dari presentasi nonpersonal dan promosi ide, barang, atau jasa oleh sponsor yang terindefikasi melalui media yang promosikan seperti (Koran, dan Majalah), Media penyiaran (radio, dan televisi), Media jaringan (telepon, kabel, satelit, dan nirkabel), Media electronic (rekaman suara, rekaman 
video, Vidiodisk, CD-ROM, halaman web), dan media display (Billboard, tanda-tanda, poster).

\subsubsection{Faktor-faktor Yang Mempengaruhi Bauran Promosi}

Menurut Swastha dan Irawan (2008:349)Menyatakan bahwa promotional mix adalah kombinasi strategi yang paling baik dari variabelvariabel periklanan, personal selling, dan alat promosi yang lain, yang semuanya di rencanakan untuk mencapai tujuan program penjualan.

\subsection{Definisi Kualitas}

Menurut Philip Kotler (2002:83) Definisi layanan setiap tindakan atau kegiatan yang dapat ditawarkan oleh satu pihak lain, yang pada dasarnya tidak berwujud tindak mengakibatkan kepemilikan apapun, Produk mungkin terkait atau tidak terkait dengan produk fisik.

Sedangkan Menurut Tjiptono (2007), Sehingga definisi kualitaspelayanan dapat diartikan sebagai upaya untuk memenuhi kebutuhan dan keinginan konsumen dan ketepatan pengiriman dalam menyeimbangkan harapan konsumen.

\subsection{Definisi Harga}

Harga suatu nilai produk, karena akan berpengaruh terhadap keuntungan produsen. Harga juga pertimbangan konsumen untuk membeli, sehingga perlu pertimbangan khusus untuk menentukan harga.Harga adalah suatu nilai tukar yang bisa disamakan dengan uang ataupun barang lain untuk maafaat yang diboleh dari suatu barang atau jasa bagi seseorang ataupun kelompok pada waktu tertentu dan tempat tertentu. Harga digunakan untuk memberikan nilai finansial pada suatu produk barang atau jasa, biasanya penggunaan kata harga berupa nominal besaran angka terhadap nilai tukar mata uang yang menunjukan tinggi rendahnya nilai suatu kualitas barang atau jasa.

\subsubsection{Tujuan Penetapan Harga}

Menurut Phiip kotler dan katler (2016:491), terdapat beberapa tujuan penetapan harga, antara laen :

\section{Kemampuan Bertahan (survival)}

Perusahaan mengejar kemampuan bertahan sebagai tujuan utama mereka jika mereka mengalami kelebihan kapalitas, persaingan ketat dan keinginan konsumen yang berubah. Selama harga menutup biaya variabel dan beberapa variabel tetap, maka perusahaan tetap berada dalam bisnis. Kemampuan bertahan merupakan tujuan jangka pendek, dalam jangka panjang perusahaan harus mempelajari cara menambah nilai atau menghadapi kepunahan.

\subsubsection{Faktor - faktor yang mempengaruhi harga.}

Menurut Mc. Carthy dalam Swastha (2010:125) adalah sebagai berikut:

\section{Tingkat Harga.}

Pada umumnya harga di tetapkan perusahaan disesuaikan dengan strategi perusahaan secara keseluruhan dalam menghadapi situasi dan kondisi yang berubah dan diarahkan untuk mencapai tujuan dan sasaran yang telah ditetapkan untuk tahun atau waktu tertentu. 


\subsection{Definisi Keputusan Pembelian.}

Pengertian Keputusan Pembelian secara umum merupakan sebuah tindakan yang dilakukan kosumen untuk membeli suatu produk, Setiap produsen pasti menjalankan berbagi stategi agar konsumen memutuskan untuk membeli produk.akan memandang suatu produk dari berbagi sudut pandang. Hal inilahyang disebut dengan tahaptahapan proses keputusan pembelian.

\subsubsection{Proses Keputusan Pembelian.}

Menurut Philip Kotler (2002) dalam jurnal keputusan pembelian, terdapat lima peran proses keputusan pembelian, sebagai berikut:

\section{Pemrakarsa (initiator)}

Seseorang yang Pertama kali menyarankan membeli suatu produk atau jasa

tertentu.

\section{Pemberi Pengaruh (influencer)}

Seseorang yang pandang ataupun nasehat memberi bobot dalam pengambilan keputusan akhir.

\subsubsection{Tahap - tahap Proses keputusan pembelian.}

Menurut Phiplip Kotler (2005:204), Ada beberapa tahap-tahap keputusan pembelian,secara berikut:

\section{Pengenalan Masalah (Problem Recognition).}

Pengenalan masalah atau kebutuhan adalah pembelian menyadari suatu perbedaan antara keadaan yang diinginkan, kebutuhan itu dapat digerakan oleh rangsangan dari dalam diri pembeli ataupun dari luar.Pemasar perlu meneliti konsumen untuk memperoleh jawaban, Apakah kebutuhn yang dirasakan atau masalah yang timbul.

2. Pencarian Informasi.

Konsumen yang mulai tertugah minatnya mungkin akan atau mungkin tidak mencari informasi yang lebih banyak lagi, konsumen yang kuat dan obyek yang dapat memuaskan kebutuhan itu tersedia, konsumen mungkin tidak berusaha untuk memperoleh informasi lebih lanjut atau sangat aktif mencari informasi sehubungan dengan kebutuhan itu.

\section{METODE PENELITIAN}

\subsection{Desain Penelitian}

Desain penelitian adalah semua proses diperlukan dalam perencanaan dan pelaksanaan penelitian. Menurut Sugiono (2008:84-85), metode kualitatif adalah pendekatan ilmiah yang memandang suatu realitas itu dapat diklasifikasikan, konkrit, teramati dan terukur, hubungan variabelnya bersifat sebab, akibat, dimana data penelitiannya berupa angka-angka dan analisisnya menggunakan statistik.Desain penelitian ini bertujuan untuk mengetahui apakah Promosi, Kualitas, Dan Harga berpengaruh terhadap keputusan pembelian sandal dan sepatu brand carvil Lampung - Yos Sudarso Bandar Lampung.

\subsection{Oprasional Variabel Penelitian}

Menurut sugiyono (2010), Operasional Variabel merupakan variabel yang 
diungkapkan dalam definisi konsep secara praktik, nyata dalam lingkungan obyek atau obyek yang diteliti. Variabel yang digunakan dalam penelitian ini adalah, variabel bebas dan variabel terikat.:

a. Variabel Bebas (Independent Variabel)Variabel bebas adalah variabel yang menyebabkan timbulnya atau perubahan variabel terikat. Variabel bebas digunakan dalam penelitian ini adalah kepribadian.

\subsection{Populasi dan sampel penelitian}

\subsubsection{Populasi}

Menurut Sugiyono (2010:117), Populasi adalah wilayah generilisasi yang terdiri dari obyek, dan subyek yang mempunyai kualitas dan krakteristik yang ditetapkan oleh penelitian untuk mempelajari dan kemudian ditarik kesimpulannya.

Sedangkan Menurut Hartono (2011:46), populasi dengan karakteristik tertentu ada yang berjumlahnya terhingga dan tidak terhingga. Penelitian hanya dapat dilakukan pada populasi yang jumlahnya terhingga saja.populasi dalam penelitian ini adalah konsumen berjumlah 75 orang pada konsumen pembelian sandal dan sepatu brand carvil Lampung - Yos Sudarso Bandar Lampung.

\subsubsection{Sampel.}

Sampel yang digunakan / diambil dengan teknik Exhaustive Sampling atau biasa disebut total sampling atau sampling jenuh yaitu teknik penentuan sampel bila semua anggota populasi digunakan sebagai sampel. Menurut Arikunto, (2006:56-57) menyatakan bahwa apabila subjek kurang dari 100, maka lebih baik sampel diambil semua sehingga penelitiannya merupakan penelitian populasi. Dalam penelitian ini populasi kurang dari 100 sehingga menggunakan total populasi yang berarti seluruh jumlah sampel adalah 73 orang pada konsumen / pembeli sandal dan sepatu brand Carvil Lampung Yos Sudarso Bandar Lampung.

\subsection{Teknik Pengumpulan Data.}

Metode pengumpulan data yang digunakan dalam penelitian ini adalah data digunakan bersumber dari data primer dan data sekunder yaitu dengan mnggunakan teknik pengumpulan data sebagai berikut:

\section{a. Data Primer}

Data yang dikumpulkan dengan menggunakan sebagai berikut:

\section{Observasi}

2. Kuesione

\subsection{Teknik Analisi Data}

Jenis penelitian ini adalah kuantitatif menggunakan kuesioner.Kuesioner adalah teknik pengumpulan data dengan memberikan daftar pertanyaan kepada responden yang telah ditetapkan dalam penelitian.

\subsubsection{Metode Analisis Data.}

Data yang diperoleh dari penyebaran kuesioner merupakan analisis sedemikian rupa agar dapat memberi manfaat dan dapat digunakan sebagai 
salah satu pertimbangan dalam pengambilan keputusan.

\subsection{Waktu Dan Tempat Penelitian.}

Waktu penelitian akan dilaksanakan kurang lebih nya selama 3 bulan yakni dari observasi lapangan hingga rencana penelitian pada bulan januari sampai dengan april 2020 yang beralamat di Jalan. Yos Sudarso, Kelurahan Pidada, Kecamatan Panjang , Kota Bandar Lampung, Kode Pos 35241 Provinsi Lampung.

\section{HASIL PENELITIAN DAN}

\section{PEMBAHASAN}

\subsection{Deskripsi Data}

\subsubsection{Gambaran Umum PT. Carvil Abadi}

Produk carvil dapet ditemukan dengan mudah disetiap sudut Negara baik diseluruh pasar tradisional dan modern (lebih dari 400 tokoh). Selain itu, produk carvil dapet ditemukan banyak lagi di Negara luar negeri seperti Singapure, Filipina, Malaysia, Timur Tengah, Maladewa, dan banyak yang akan datang. Selain itu, agar terjangkau bagi konsumen, sejak tahun 2013 Carvil mempunyai tokoh ritel carvil sendiri yang terjual berbagai macam produk carvil dari pakai hingga alas kaki. "pada akhir 2014, kami berhasil membuka hampir 100 toko ritel baik yang dimiliki maupun toko waralaba. "kata Unang selaku Operational Maneger PT.Carvil Abadi Indonesia. Tentunya Perkembangan bisnis warabala carvil terbilang cukup bagus dengan adanya penambahan calon franchisee, beberapa mitra pun membuka lebih dari satu took. Bahkan sampai saat banyak dari mereka meminta melanjutkan kemitraan walaupun belum habis kemitraannya. Beberapa alasan dari mitra, mereka yakin akan brand carvil akan brand pastinya saat kuat, carvil juga menjaga mitra dengan membangun kepercayaan dan keterbukaan dalam informasi hasil usaha yang diperoleh dengan benar tentunya.

\subsubsection{Umum Responden}

Populasi dalm penelitian ini adalah konsumen Carvil Lampung - Yos Sudarso Bandar Lampung ini 75 ditentukan dengan teknik total sampling.

\subsection{Hasil Penelitian}

\subsubsection{Instrumen Penelitian}

1. Uji Validitas

Pengujian validitas bertujuan untuk mengetahui apakah butir kuesioner benar-benar telah mengukur atau mengungkapkan fakta apakah butir pertanyaan dari masing-masing variabel mempunyai korelasi yang bermakna (signifikasi) dengan jumlah skor faktornya.Dalam penguji validitas ini data yang digunakan berasal dari uji coba penelitian terhadap 20 responden yang merupakan masyarakat umum, pada pengaruh promo, kualitas, dan harga terhadp keputusan pembeliaan brand carvil di carvil lampung Bandal Lampung.Penguji validitas pada variabel pengaruh promosi, dilakukan dengan perhitungan korelasi peason

Hasil Pengujian Validitas Pengaruh Promosi $\left(\mathrm{X}_{1}\right)$ 
Scale Mean if Item Deleted Scale

Variance if Item Deleted Corrected Item-Total Correlation Cronbach's Alpha if Item Deleted

Item 1

$\begin{array}{lll}16.40 & 2.884 & .628\end{array}$

.771

Item 2

$\begin{array}{lll}16.35 & 2.976 & .517\end{array}$ .806

Item 3

$\begin{array}{lll}16.40 & 2.779 & .552\end{array}$ .801

$\begin{array}{llll}\text { Item } 4 & 16.40 & 3.200 & .605\end{array}$ .783

$\begin{array}{llll}\text { Item } 5 & 16.45 & 2.787 & .775\end{array}$ .730

Sumber:Ouput SPSS 20, 2020

Hasil penguji Validitas Pengaruh Kualitas $\left(\mathbf{X}_{2}\right)$

Item-Total Statistics

Scale Mean if Item Deleted Scale

Variance if Item Deleted Corrected

Item-Total Correlation Cronbach's

Alpha if Item Deleted

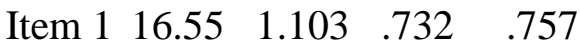

$\begin{array}{lllll}\text { Item } 2 & 16.55 & 1.208 & .569 & .808\end{array}$

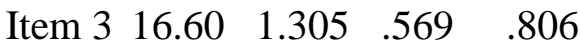

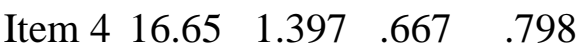

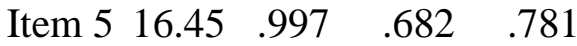

\section{Hasil Penguji Validitas Harga (X3)}

Item-Total Statistics

Scale Mean if Item Deleted Scale Variance if Item Deleted Corrected
Item-Total

Correlation

Cronbach's Alpha if Item Deleted

$\begin{array}{lllll}\text { Item } 1 & 16.50 & 1.105 & .620 & .717\end{array}$

$\begin{array}{lllll}\text { Item } 2 & 16.70 & 1.484 & .638 & .742\end{array}$

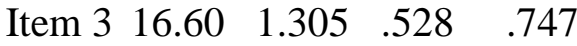

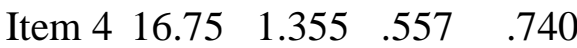

$\begin{array}{lllll}\text { Item } 5 & 16.45 & 1.103 & .565 & .745\end{array}$

Sumber : Ouput SPSS 20, 2020 (Data Diolah)

Hasil Penguji Validitas Keputusan Pembelian (Y)

\section{Uji Validitas Keputusan Pembelian Y}

Item-Total Statistics

Scale Mean if Item Deleted Scale

Variance if Item Deleted Corrected Item-Total Correlation Cronbach's Alpha if Item Deleted

$\begin{array}{lllll}\text { Item } 1 & 17.00 & 2.000 & .812 & .825\end{array}$

$\begin{array}{lllll}\text { Item } 2 & 16.95 & 2.261 & .767 & .835\end{array}$

$\begin{array}{lllll}\text { Item } 3 & 17.05 & 2.576 & .623 & .869\end{array}$

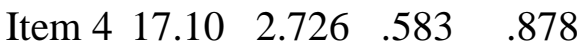

$\begin{array}{lllll}\text { Item } 5 & 16.90 & 2.200 & .776 & .833\end{array}$

Sumber:Ouput SPSS 20, 2020 (Data Diolah).

\section{Uji Realibitas}

Uji realibitas kuesioner dilakukan dengan tujuan untuk mengetahui konsisten derajat ketergantungan dan stalibitas dari alat ukur, sedangkan menurut sugiono (2010) yang 
mengemukakan bahwa dikatakan reliable jika membelikan nilai cronbach's alpa> 0,60. Dari hasil uji reliabilitas yang dilakukan dengan menggunakan program statistik SPSS 20 didapat dari hasil cronbach`s alpa lebih besar dari 0,60 untuk ketiga variabel yaitu $\mathrm{X}_{1}, \mathrm{X}_{2}, \mathrm{X}_{3}$ dan $\mathrm{Y}$. Hasil reliabilitas variabel-variabel dapat dilihat dari tabel berikut ini:

Tabel 4.10

\section{Hasil Uji Reliabilitas}

Variabel Cronbach`s $\quad r \quad$-Kritis Keterangan

X1 $0.815 \quad 0.60 \quad$ Reliabel

$\begin{array}{llll}\mathrm{X} 2 & 0.826 & 0.60 & \text { Reliabel }\end{array}$

$\begin{array}{llll}\text { X3 } & 0.780 & 0.60 & \text { Reliabel }\end{array}$

Y $\quad 0.876 \quad 0.60 \quad$ Reliabel

Sumber: Output SPSS 20, 2020 (Data Diolah)

Tabel 4.12

Nilai Uji Normalitas KolmogrovSmornov

One-Sample Kolmogorov-Smirnov Test Unstandardized Residual

$\mathrm{N} \quad 75$

Normal Parametersa,bMean $\quad .00$

Std. Deviation 1.084

Most Extreme Differences Absolute .077

Positive .077
Negative $\quad-.068$

Kolmogorov-Smirnov Z $\quad .666$

Asymp. Sig. (2-tailed).767

a. Test distribution is Normal.

b. Calculated from data.

Sumber : Ouput SPSS 20, 2020 (data diolah)

Hasil Uji Multikolinearitas

\section{Coefficientsa}

Model Unstandardized Coefficients Standardized Coefficients $\mathrm{T}$

Sig. Collinearity Statistics

B Std. Error Beta Tolerance VIF

$1 \quad$ (Constant) $\quad$-9. 2.979 1.3.63 .002

Promosi $\quad .202 \quad .070$

$\begin{array}{llll}.230 & 2.909 & .005 & .925\end{array}$

1.081

Kualitas $\quad .871 \quad .121$

$\begin{array}{llll}.556 & 7.212 & .000 & .973\end{array}$

1.028

Harga $\quad .413 \quad .100 \quad .326$

$\begin{array}{llll}4.114 & .000 & .919 & 1.088\end{array}$

a. Dependent Variable: Keputusan Pembelian

Sumber : Ouput SPSS 20, data diolah (2020)

\section{Uji Heteroskedastisitas}

Uji Heteroskedastisitas adalah dimana keadaan model regresi terjadi 
ketidaksamaan varian dari residual pada

satu pengamatan yang lain. Model

regresi yang baik tidak terjadi

heteroskedastisitas

Tabel 4.16

Hasil Uji Heteroskedastisitas

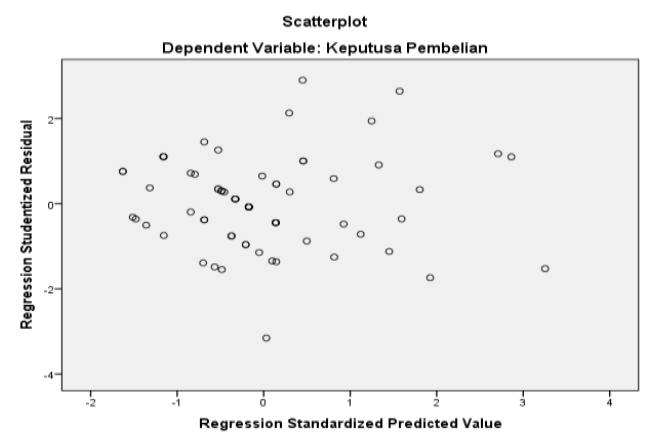

Sumber data : Ouput SPSS 20, 2020

Berdasarkan Gambar 5.4 dari ouput diatas diketahui bahwa titik-titik tidak membentuk pola yang jelas.Titik-titik menyebar diatas dan dibawah 0 pada sumbu Y. jadi dapat disimpurkan bahwa pada uji heteroskdastisitas ini tidak mengalami masalah heteroskdastisitas ini tidak mengalami masalah heteroskedastisitas dalam model regresi.

\subsubsection{Uji Hipotesis}

a. Uji f (Secar Slimultan)

Uji slimutan (uji f) dilakukan untuk menggambarkan seberapa jauh variabel independen secara bersama-sama dalam

menerangkan variabel

dependen.Untuk memastikan

apakah variabel independen

terdapa dalam bersama-sama

berpengaruh terhadap nilai

variabel dependen yaitu dengan

membandingka $\mathrm{F}$ tabel dengan $\mathrm{F}$

hitung.

Menentukan signifikasi (a) yaitu sebesar $5 \%$ dasar pengambilan keputusan dalam penelitian ini adalah :

a. Jika fhitung $>f_{\text {tabel }}$, maka variabel independen (X) berpengaruh terhadap variabel dependen (Y).

b. Jika fitung < dari $\mathrm{f}$ tabel maka variabel independe $(\mathrm{X})$ tidak berpengaruh terhadap variabel dependen $(\mathrm{Y})$ 
Tabel 4.17

Uji f (secara Simultan)

ANOVA ${ }^{\mathrm{a}}$

\begin{tabular}{|l|l|l|l|l|l|}
\hline Model & Sum of & Mf & Mean & F & Sig. \\
& Squares & & Square & & \\
\hline Regres & 124.91 & 3 & 41.639 & 33.9 & $.000^{\mathrm{b}}$ \\
sion & 6 & & 1.226 & 69 & \\
Residu & 87.031 & 71 & & & \\
1 & & & & & \\
al Total & 711.94 & 74 & & & \\
\hline
\end{tabular}

a. Dependent Variable: Keputusan Pembelian

b. Predictors: (Constant), Harga, Kualitas, Promosi

Sumber : Ouput SPSS 20, data diolah (2020)

\subsubsection{Keterbatasan Penelitian}

1. Keterbatasan waktu dan biaya sehingga penelitian hanya menyebarkan kuesioner ke pelanggan/ konsumen sandal dan sepatu brand carvil Lampung - yos sudarso Bandar Lampung.

2. Keterbatasan waktu responden terhadap penelitian yang membuat responden kurang terfokus pada pernyataan yang diajukan

C. Analisis Regresi Linier Berganda
Analisi regresi berganda digunakan untuk mengetahui arah hubungan antara variabel independen dan variabel dependen.Persamaan regresi dapat dilihat dari tabel hasil uji coefficient berdasarkan ouput SPSS 20 terhadap ke tiga variabel independen yaitu faktor Pengaruh Promosi, Kualitas, Harga dan faktor Keputusan Pembelian

Berdasarkan tabel 5.6 diatas terlihat bahwa nilai konstanta sebesar 9.643 dan koefisien b1 0.202, b2 0,871, b3 0.413.nilai konstanta dan koefisien regresi $(\mathrm{X} 1, \mathrm{X} 2, \mathrm{X} 3)$ ini dimasukan dalam persamaan regresi berganda sebagai berikut :

$\mathrm{Y}=\mathrm{a}+\mathrm{b} 1 \mathrm{X} 1+\mathrm{b} 2 \mathrm{X} 2+\mathrm{b} 1 \mathrm{X} 3+\mathrm{e}$

$9643+202+871+413)$

Sehingga persamaan regresinya menjadi sebagai berikut :

1. Nilai Konstanta sebesar 9.643 hal ini menunjukan apabila bahwa variabel independen Pengaruh Promosi, $\quad\left(\mathrm{X}_{1}\right)$, 
Pengaruh Kualitas

$\left(\mathrm{X}_{2}\right)$,Pengaruh Harga $\left(\mathrm{X}_{3}\right)$, tidak

mengalami perubahan atau nilai

nol, maka nilai dari variabel

Keputusan Pembelian (Y)

adalah sebesar 9.643.

2. Faktor Pengaruh Promosi $\left(\mathrm{X}_{1}\right)=$ 0,202

Merupakan nilai koefisien regresi variabel Pengaruh Promosi $\left(\mathrm{X}_{1}\right)$ terhadap variabel Keputusan Pembelian (Y) artiny jika variabel Pengaruh Promosi $\left(\mathrm{X}_{1}\right)$ mengalami ditingkatkan $1 \%$, maka tingkat Keputusan Pembelian (Y) akan mengalami kenaekan sebesar 0.202 koefisien bernilai negative ntara Pengaruh Promosi $\left(\mathrm{X}_{1}\right)$ dan Keputusan Pembelian (Y) berhubungan Negatif.

3. Faktor Pengaruh Kualitas $\left(\mathrm{X}_{2}\right)$ $=0.871$

Merupakan nilai koefisien regresi variabel Pengaru Promosi $\left(\mathrm{X}_{2}\right)$ terhadap variabel Keputusan Pembelian (Y) artinya jika Faktor
Pengaru Kualitas $\left(\mathrm{X}_{2}\right)$ mengalami ditingkatkan 1\%, maka tingkat Keputusan Pembelian (Y) akan mengalami peningkatan 0.871 maka koefisien bernilai positif artinya antara Pengaruh Kualitas $\left(\mathrm{X}_{2}\right)$ dan Keputusan Pembelian (Y) berhubungan positif.

4. Faktor Pengaruh Harga

Merupakan nilai koefisien regresi variabel Pengaruh Harga $\left(\mathrm{X}_{3}\right)$ terhadap variabel Keputusan Peambelian (Y) artinya jika faktor Pengaruh $\operatorname{Harga}\left(\mathrm{X}_{3}\right)$ mengalami ditingkatkan 1\%, maka tingkat Keputusan Pembelian (Y) akan mengalami kenaikan sebesar 0.413. maka koefisien bernilai positif artinya diantara fartor Pengaruh Harga $\left(\mathrm{X}_{3}\right)$ dan Keputusan Pembelian (Y) berhubungan Positif

\section{KESIMPULAN DAN SARAN}

\subsection{Kesimpulan}

Berdasarkan hasil penelitian yang telah dilakukan guna mencari bukti secara 
emperis tentas pengaruh promosi,

kualitas, dan harga terhadap keputusan

pembelian sandal dan sepatu brand

Carvil Lampung - Yos Sudarso Bandar

Lampung.

1. Variabel promosi, kualitas dan harga secara Modelregresi berganda diperoleh bersamaan berpengaruh secara signifikan terhadap keputusan

2. pembelian Pelanggan / konsumen, dari hasil analisis regresi bahwa secara bersama variabel independen. Ini dapat dibuktikan dari nilai f hitung sebesar 33.969 dengan signifikasi (sig) lebih kecil dari 0.05 .

3. Berdasarkan koefisien determinasi sebesar 0.5720dapat diketahui bahwa variasi perubahan dari pengaruh keputusan pembelian dapat dijelaskan oleh variasi dari 3 variabel independen (promosi, Kualitas, dan Harga) yang mempengaruhi keputusan pembelian, nilai $\mathrm{R}^{2}$ $($ Determinan $)=0.5720$ menunjukan $572 \%$ variabel bebas berpengaruh
$\mathrm{Y}=\mathrm{a}+\mathrm{b} 1 \mathrm{x} 1+\mathrm{b} 2 \mathrm{X} 2+\mathrm{B} 3 \mathrm{X} 3$.

\subsection{Saran}

Dari simpulan tersebut ada beberapa saran yang penulisan ajukan yang dapat dijadikan acuan sesuai dengan hasil penelitian yaitu diantaranya :

1. Kegiatan promosi sandal dan sepatu brand carvil Lampung - Yos Sudarso Bandar Lampung yang telah mampu menarik perhatian konsumen tersebut hendaknya tetep dipertahankan dan berusaha meningkatkan Frekuensi penayanganya dimedia masa agar semakin dekat dengan calon konsumen terutama untuk produkproduk baru.

2. Perusahaan hendaknya menyesuaikan harga dengan kualitas 
produk, melalui model sandal dan

sepatu yang trend agar konsumen

tertarik kepada model dan kualitas

yang ditawarkan sandal dan sepatu

brand Carvil Lampung-Yos Sudarso

Bandar Lampung .

3. Sebelum melakukan pembelian, konsumen hendaknya lebih berhatihati dalam memilih sandal dan sepatu, jangan hanya tertarik dengan harga yang ditawarkan, kualitas dan model yang dibuat dan iklan yang ditayangkan dari perusahaan akan lebih trend lagi agar konsumen tertarik dengan brand carvil yang diperoleh.

\section{DAFTAR PUSTAKA}

Alma Buchari.(2013:179).Pengertian Bauran Promosi.Penerbit :Alfabeta cipta: Bandung.

Amstrong, Gary \& amp; Philip, Kotler.(2013). Dasar-Dasar Pemasaran. Jilid I, Penerbit: Bahasa Alexander Sindo Dan Benyamin Molan. Prenhalindo. :Jakarta.

Basrowi.(2010).Memahami Penelitian Kualitatif. Penerbit Rineka Cipta:Jakarta.

Brantas.(2009).Dasar-Dasar

Manajemen. Penerbit Alfabeta: Bandung.
Daryanto.(2011). Pedoman Praktis Memahami pengantar manajemen. Penerbit Andi: Yogyakarta. Jakarta.

Fahmi Irham.(2011).Analisis Laporan Akuntansi. Penerbit:Alfabeta: Bandung.

Haryani.(2006).Azas-azaz marketing Liberty. Promosi,Kualitas, dan Harga terhadap keputusan pembelian. :Kabupaten Purworejo: Jurnal Haryani (2006)

H. B. Siswanto.(2013). Pengantar Manajemen.

Aksara:Jakarta

Swasta dan Irawan.(2008).Manajemen Pemasaran Modern. Penerbit:Liberty: Yogyakarta.

Rosad Dan Suparyanto. (2015). Manajemen Pemasaran. Penerbit:IN MEDIA: Bogor. Sugiyono.(2010).Statistika Untuk Penelitian. Penerbit:

Alfabeta:Bandung.

Lupiyoadi, Rambat.(2013:179). Pengertian unsur-unsur bauran promosi Pemasan, Penerbit Edisi ketiga Salemba:Jakarta.

Sumber: http://www.carvil.co.id.

Sumber:http://www.pendidik.co.id.

Sumber:http://www.cashbash.com.

Sumber data diolah SPSS,20 